\title{
DYNAMICS OF DIAMOND GROWTH: EVIDENCE FROM ISOTOPE AND FTIR TRENDS
}

\author{
G.P. Bulanova ${ }^{1}$, D.G. Pearson ${ }^{2}$, E.H. Hauri ${ }^{3}$, H.G. Milledge ${ }^{4}$ and Y.P. Barashkov ${ }^{5}$ \\ ${ }^{1}$ University of Bristol, UK; ${ }^{2}$ Durham University, UK; ${ }^{3}$ Carnegie Institution of Washington, U.S.A. ; ${ }^{4}$ University College, \\ London, UK; ${ }^{5}$ Diamond and Precious Metal Institute, Siberian Branch, RAS, Sakha Republic, Russia
}

\begin{abstract}
The inhomogeneous nature of many diamonds from kimberlites reflects evolution of their growth conditions. Six peridotitic and 8 eclogitic Yakutian macrodiamonds displaying changing internal growth morphology have been studied for carbon (C) and nitrogen $(\mathrm{N})$ isotopes and $\mathrm{N}$ content and aggregation. Using cathodoluminescence (CL) images of central polished sections of diamonds as maps, $\mathrm{C}$ and $\mathrm{N}$ isotopes and $\mathrm{N}$ content were measured by secondary ion mass spectrometry (SIMS) in traverses from core to rim of the crystals. $\mathrm{N}$ concentration and aggregation were also determined in the same traverses by Fourier transform infrared spectroscopy (FTIR).
\end{abstract}

In the studied diamonds the $\mathrm{N}$ content and degree of aggregation decrease from the core to the rim zones. In general, both SIMS and FTIR N content measurements are in agreement, showing similar trends for the same diamonds. The SIMS results are more variable because of their higher resolution of sampling (a few microns from the surface of the single growth zones), while FTIR analyses represent averages of a few diamond zones (Harte et al., 1999; Hauri et al., 1999, Bulanova et al., 2002).

All peridotitic diamonds measured have heavy $\mathrm{C}$ isotope composition ( -8.9 to -2 per mil). No common overall isotopic trend between the stones was found. The total internal variation in $\mathrm{C}$ isotope compositions within studied individual peridotitic diamonds was only $4 \%$, consistent with levels of $\mathrm{C}$ isotope fractionation expected from simple fractionation of a fluid phase in the mantle (Deines, 1980). Typically, peridotitic diamonds show very little internal variation in $\delta^{13} \mathrm{C}$. Significant internal isotopic variations are observed in three peridotitic diamonds with complex internal structures. Within these diamonds, $\delta^{13} \mathrm{C}$ increases and $\delta^{15} \mathrm{~N}$ decreases from the core to the rim growth zones.

All 8 eclogitic diamonds studied also have heavy carbon isotope compositions ( -8.8 to +1.7 per mil). Eclogitic diamonds show larger magnitude internal isotopic variations compared to peridotitic diamonds.
For instance, $\delta^{13} \mathrm{C}$ varies by 4 to $6 \%$ within individual crystals. A smooth decrease in $\delta^{13} \mathrm{C}$ from the core to the rim zones was identified in eclogitic diamonds showing simple, concentric growth banding in the octahedral form. However, variation does exist. One eclogitic diamond from the Mir pipe displayed variable $\delta^{13} \mathrm{C}$ in the core zone, accompanied by variable $\mathrm{N}$ content and $\mathrm{N}$ isotopic composition. The rim zone of the same diamond was very homogenous in all these parameters.

The range of $\mathrm{N}$ isotope concentration in the core of all studied diamonds is wide $(-8.8$ to $+9.5 \%$ o), but rim values vary only from -6.7 to $0.37 \%$. The peridotitic diamonds show a different scale of decrease of $\delta^{15} \mathrm{~N}$ from their cores to rims, while eclogitic diamonds display both decreases and increases in $\delta^{15} \mathrm{~N}$

A wider range of isotopic values in the cores may reflect either varying source, or, the likelihood that conditions of growth during diamond nucleation were far from equilibrium compared to conditions prevailing during the latter stages of diamond growth, reflected by the narrower compositions of the rims. The trends evident in $\mathrm{C}$ and $\mathrm{N}$ isotopic composition within single diamonds enable interpretation of the type of processes responsible for diamond formation. Based on the results of thermodynamic models (Deines, 1980; Deines et al., 1989) our data are consistent with peridotitic diamonds forming by precipitation from $\mathrm{CO}_{2}$-rich fluid. In the frame of the same model the eclogitic diamonds were more likely grown from $\mathrm{CH}_{4}$-rich fluids that underwent isotopic fractionation.

\section{INTRODUCTION}

In this study we present data and interpretation of isotopic trends measured within individual Yakutian diamonds that show obvious features relating to changing growth conditions. The results of our previous investigations and characterisation of some of these diamonds have been reported in part before (Bulanova, 1995; Taylor et al., 1995; Taylor et al, 1998; Hauri et al., 1999; Pearson et al., 1999). Here we present new N isotopic and $\mathrm{N}$ abundance data obtained by SIMS, together with $\mathrm{N}$ abundance and aggregation data 
determined by FTIR, summarising them with previously published results to provide an overview of the evolutionary trends that can be distinguished. We integrate this information in order to constrain the diamond growth conditions.

\section{SAMPLES AND METHODS OF STUDY}

Twelve gem quality octahedral diamonds $(3-6 \mathrm{~mm})$ with distinctive internal structures were selected for study. Six peridotitic and 8 eclogitic diamonds from kimberlite pipes Mir, Udachnaya and 23rd Party Congress (Yakutia) were sawn and polished on their dodecahedron planes until $0.7-1 \mathrm{~mm}$ thin central plates were produced. The internal structure of diamonds was studied by CL imaging, used as the maps for the following core-rim measurements of $\mathrm{N}$ content and aggregation and $\mathrm{C}$ and $\mathrm{N}$ isotopes in the diamonds. Hydrogen and $\mathrm{N}$ concentrations and $\mathrm{N}$ aggregation were measured by FTIR. C and $\mathrm{N}$ isotopic composition were analysed by SIMS. Details of all analytical techniques can be found in Hauri et al. (2002) and Bulanova et al (2002). Uncertainties on the determination of $\delta^{13} \mathrm{C}$ are $+/-0.6 \%$ \% $\quad 0$. Reproducibility of $\delta^{15} \mathrm{~N}$ measurements is +/- 2 per mil but the heterogeneity of the standard used in this study limits accuracy to $6 \%$ o $(2 \sigma)$.

\section{RESULTS}

\section{GENERAL ISOTOPIC TRENDS SHOWN BY DIAMOND GROUPS}

\section{Carbon isotopes}

All 6 peridotitic diamonds have heavy $\mathrm{C}$ isotope composition (Fig 1). Two diamonds have heavy compositions relative to typical mantle carbon, the others are the same or lighter. The range in $\delta^{13} \mathrm{C}$ values of the cores of the P-type diamonds ( -9 to $-3 \%$ ) is slightly more variable than the total range shown by the rims $(-6.7$ to $-3 \%$ ) of the different diamonds. The rim $\delta^{13} \mathrm{C}$ values are within approx. 2 per mil of the typical mantle value of -5.5 per mil (Fig. 1 ). This may indicate that the rim compositions of each of the diamonds grew from fluids that had changed to more typical mantle values.

The three P-type diamonds from Mir have core $\delta^{13} \mathrm{C}$ values that are heavier than the cores of diamonds from the Udachnaya and the 23rd Party Congress pipes. In

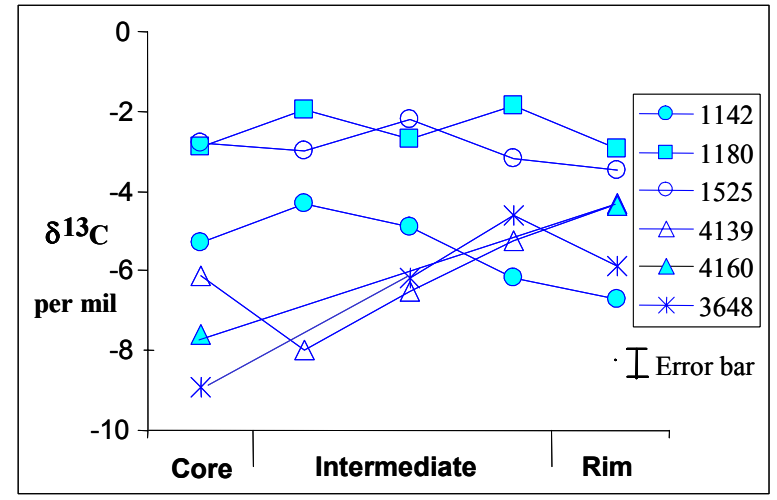

Figure 1: Core-rim traverses of $\mathrm{C}$ isotope composition determined by SIMS for some peridotitic Yakutian diamonds (1142, 1180, 1525 - Mir; 4139, 4160 - 23rd Party Congress; 3648 - Udachnaya kimberlite pipes).

traverses made across the whole crystals, all three Mir P-type diamonds show minor variations in carbon isotope composition within analytical error and of doubtful significance (Fig. 1). In contrast, the two diamonds from the 23rd Party Congress pipe and one from Udachnaya show a distinct increase in $\delta^{13} \mathrm{C}$ from core-rim that is outside of analytical error (Fig. 1).

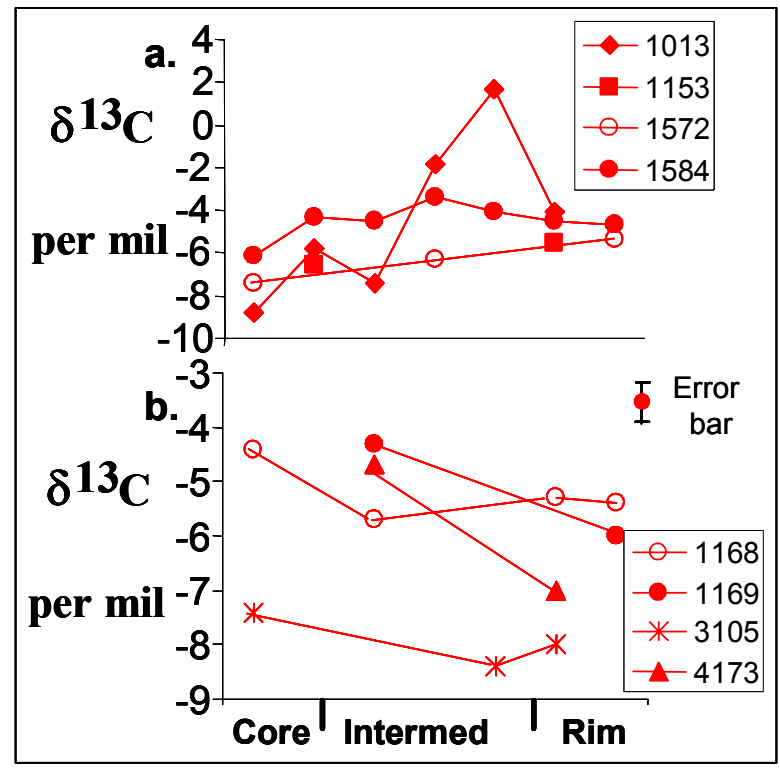

Figure 2: Core-rim traverses of $\mathrm{C}$ isotope composition determined by SIMS for some eclogitic Yakutian diamonds (3105 - Udachnaya; 4173 - 23d Party Congress; all others Mir kimberlite pipe).

All 8 eclogitic diamonds belong to the group of eclogitic heavy diamonds relative to the light and ultraheavy types (Bulanova et al., 2002; Fig. 2). Four crystals from Mir become heavier away from the core. Three stones have smooth, gradational changes of $\delta^{13} \mathrm{C}$ 
while one (sample 1013) displays very large variations in the core-intermediate zones (Fig. 2a), but with an overall trend in $\delta^{13} \mathrm{C}$ that becomes heavier away from the core. Other E-type diamonds show trends that are the reverse of this, i.e., $\delta^{13} \mathrm{C}$ values decrease from core to rim zones (Fig. 2b).

\section{Nitrogen isotopes}

The core-rim diamond traverses for $\mathrm{N}$ isotopes are shown on Fig.3. The range of $\mathrm{N}$ isotope concentration in the core of all studied diamonds is wide ( -8 to $+9.5 \%$ o), but rim values vary only from -6.7 to $0.37 \%$. The peridotitic diamonds show a different scale of decrease of $\delta^{15} \mathrm{~N}$ from the core to the rims, while eclogitic diamonds display both minor decreasing and increasing $\delta^{15} \mathrm{~N}$ trends (Fig. 3).

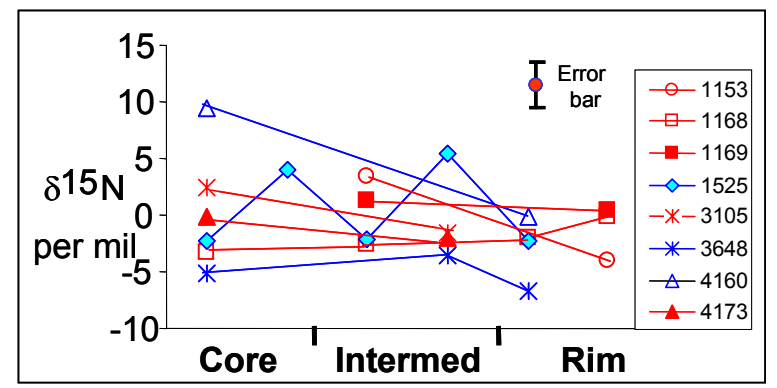

Figure 3: Core-rim traverses of $\mathrm{N}$ isotope composition determined by SIMS for the Yakutian diamonds. Red eclogitic and blue-peridotitic diamonds; identification of pipes is given on Figs 1 and 2; diamond 1013 is presented separately on Fig. 5.

\section{ISOTOPIC AND FTIR TRENDS FOR SOME INDIVIDUAL DIAMONDS}

\section{Peridotitic diamonds}

Diamond 4160 exhibits a complex internal structure with a rounded core zone having yellow CL colour, followed by a layer by layer grown octahedral intermediate and rim zones with blue CL colour. A reconnaissance core-rim traverse through the diamond revealed broad co-variations: $\mathrm{N}$ content, aggregation state and $\delta^{15} \mathrm{~N}$ values decrease in the traverse core-rim, while $\delta^{13} \mathrm{C}$ increases (Figs. 1, 3).

Diamond 1525 has simple octahedral zonation with very different optical properties between the growth zones (Taylor et al., 1995). The inner core has high $\mathrm{N}$ content, which is fully aggregated. The core is decorated by a thin zone of type II diamond (very low $\mathrm{N}$ content). The intermediate area is composed of the high $\mathrm{N}$ sub-zones and low $\mathrm{N}$ diamond sub-zones with slip lines, which arise from plastic deformation. The rim contains moderate nitrogen with a low degree of aggregation. SIMS measurements show complex relationships between $\delta^{13} \mathrm{C}$ and $\delta^{15} \mathrm{~N}$ (Fig. 1, 3). The most important observation is a dramatic change of $\mathrm{N}$ isotopic composition in the intermediate area of the diamond. In this region, positive $\delta^{15} \mathrm{~N}$ occurs in the low $\mathrm{N}$ sub-zones with slip lines and negative $\delta^{15} \mathrm{~N}$ values appear in the high-N sub-zones.

\section{Eclogitic diamonds}

Diamond 1013 was partly described by Hauri et al. (1999), so here we integrate the isotopic composition with $\mathrm{N}$ content and aggregation for the same zones in traverse via the crystal.

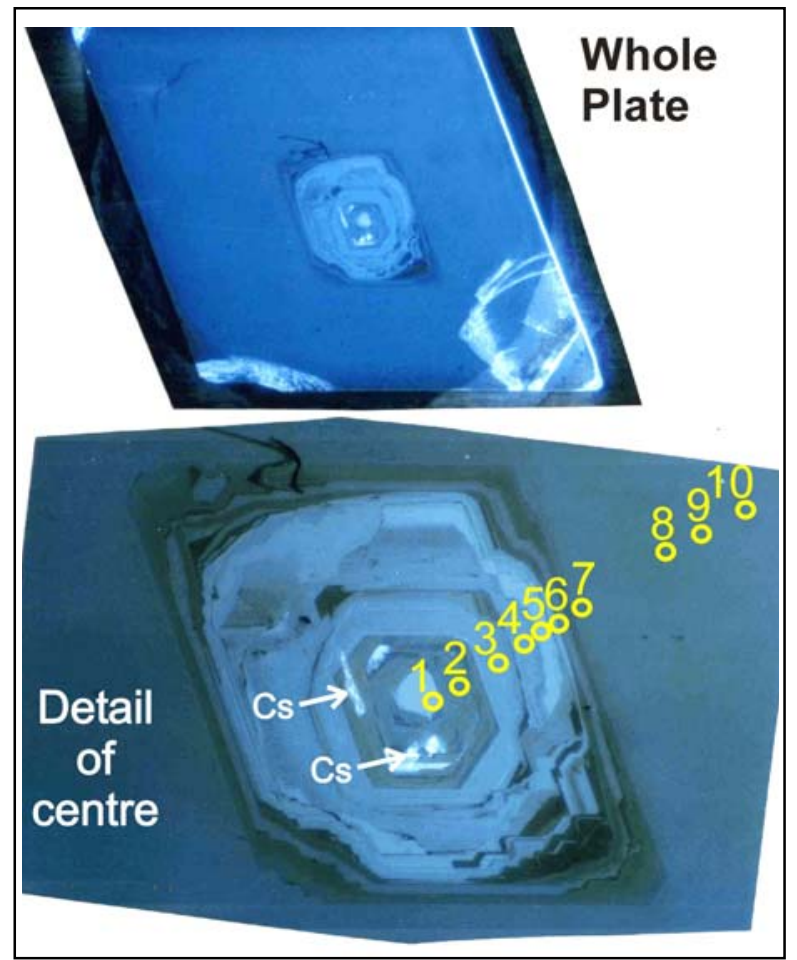

Figure 4: CL image of eclogitic diamond 1013 with SIMS traverse. Width of crystal $5 \mathrm{~mm}$; $\mathrm{Cs}$ - coesite inclusions.

The resulting trends display a large- scale inhomogeneity in the small core and intermediate growth zones followed by a very homogeneous, thick rim (Fig. 4). In general $\delta^{13} \mathrm{C}$ positively correlates with $\delta^{15} \mathrm{~N}$, both showing a negative correlation with $\mathrm{N}$ abundance (Fig. 5). The degree of $\mathrm{N}$ aggregation is very high in the core and low in the rim. The examination of the exact points of SIMS measurements on the CL image of the diamond gives some explanation for this phenomenon. There is a large change in all three parameters from the internal N-rich core zone (point 1) 
to the low-N external core zone (point 2, Fig. 4, 5). A high magnification CL image shows that this low $\mathrm{N}$ zone has features of deformation and contains widelyspaced, randomly distributed large platelets where presumably $\mathrm{N}$ is accumulated. Therefore it is possible that low $\mathrm{N}$ concentrations given by SIMS analysis may result from the analytical spot being placed between $\mathrm{N}$ rich platelets in low-N regions. Both $\delta^{13} \mathrm{C}$ and $\delta^{15} \mathrm{~N}$ change towards heavier compositions from inner (point 1) to the outer core (point 2, Figs. 4, 5). In the low N sub-zones of the intermediate area, both isotope signatures further increase, $\delta^{15} \mathrm{~N}$ up to positive value (points 3, 4). In the following N-rich sub-zones of this area (points 5, 6), both $\delta^{13} \mathrm{C}$ and $\delta^{15} \mathrm{~N}$ turn back to lighter compositions (Fig, 5). In the optically uniform thick diamond rim (points 7-10) $\mathrm{N}$ is high, whilst $\delta^{13} \mathrm{C}$ and $\delta^{15} \mathrm{~N}$ have almost uniform negative values.

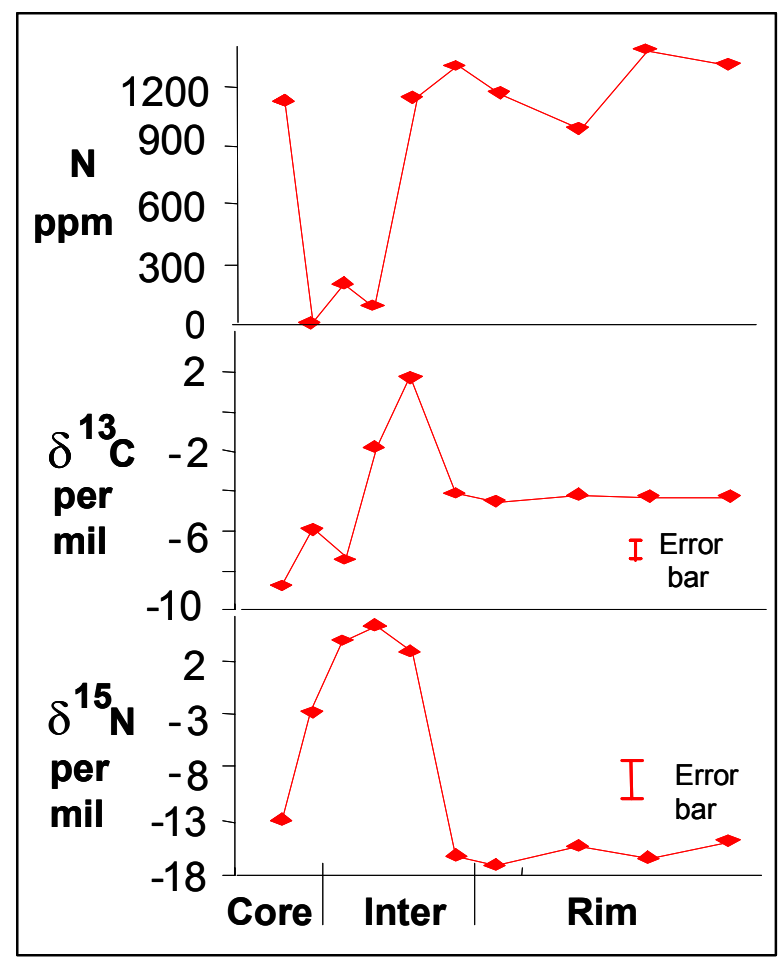

Figure 5: SIMS - FTIR core-rim traverses for eclogitic diamond 1013. Error bar $(2 \sigma)$ for $\mathrm{N} \mathrm{ppm} \mathrm{is} 1 \%$.

In spite of the eclogitic paragenesis, the 1013 isotopic trend covers values typical for peridotitic and eclogitic ultra-heavy diamonds on worldwide fields for $\mathrm{C}$ and $\mathrm{N}$ isotope composition of diamonds, as summarised in Bulanova et al. (2002).

Diamond 1168 has a complexly zoned octahedral core, with plastic deformation slip lines and regions containing gigantic platelets (Taylor et al., 1995). The core is surrounded by a cuboid growth intermediate zone, overgrown by octahedral rim zone.

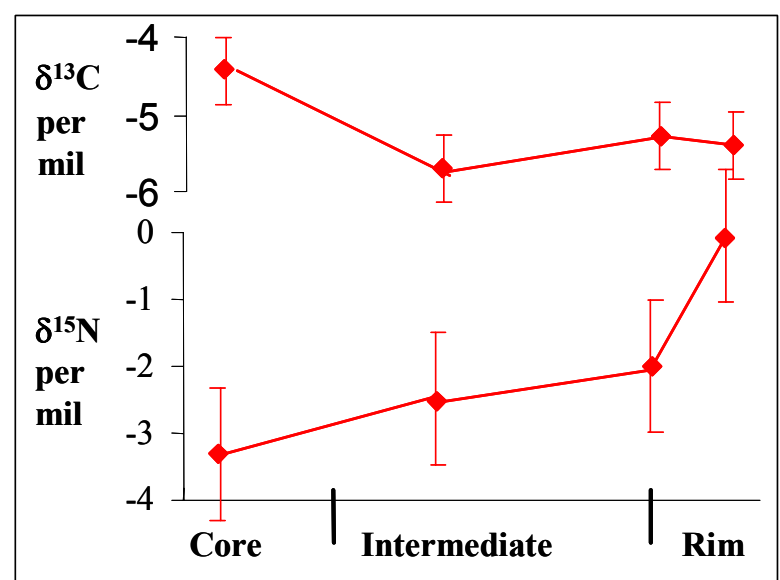

Figure 6: SIMS core-rim traverses for eclogitic diamond 1168.

The traverse across the diamond displays a positive correlation of $\mathrm{N}$ content and $\delta^{13} \mathrm{C}$. $\mathrm{C}$ isotopes become slightly lighter away from the core, having negative correlation with $\delta^{15} \mathrm{~N}$ (Fig. 6).

\section{DISCUSSION AND CONCLUSIONS}

Analytical traverses from core to rim of individual diamonds of peridotitic and eclogitic paragenesis reveal that their core regions have a much wider range in isotopic composition than their rims. This systematic variation could be interpreted as a reflection of the lack of equilibrium during the nucleation and early stages of growth compared with stable, closer to equilibrium growth conditions that prevailed during formation of the intermediate and rim diamond zones.

The wide range of $\mathrm{N}$ isotopic compositions in the diamond cores, that include positive $\delta^{15} \mathrm{~N}$ values, contrasts with the more restricted and negative $\delta^{15} \mathrm{~N}$ values measured in the rim zones. These variations might signify presence of crustal $\mathrm{N}$ in the system at the stage of diamond nucleation. Further growth of the intermediate and rim diamond zones took place under more stable conditions where fluids were dominated by mantle-derived $\mathrm{N}$, indicating the evolution of the system to fluids originating from deeper levels of the mantle. This suggestion is supported by $\delta^{13} \mathrm{C}-\delta^{15} \mathrm{~N}$ correlation in the diamonds 4160 and 1153, which have the most positive ("crustal") $\delta^{15} \mathrm{~N}$ signatures (Fig. 1-3). In these diamonds $\delta^{15} \mathrm{~N}$ becomes lighter and $\delta^{13} \mathrm{C}$ heavier from core to rim, in agreement with the trend 
for the isotopic change expected for mixing crustal and mantle derived fluids during subduction (Navon, 1999).

Relationships between $\mathrm{N}, \delta^{13} \mathrm{C}$ and $\delta^{15} \mathrm{~N}$ for individual diamonds are complex and no overall systematic trends emerge from the study of this sample set. The most important observation is the decrease of $\mathrm{N}$ content and simultaneous small scale increase or decrease of $\mathrm{C}$ and $\mathrm{N}$ isotopes during diamond formation, suggesting a continuous growth event with accompanying isotopic fractionation in a closed system.

The reasons of large-scale variations in $\mathrm{N}$ content negatively correlating with $\mathrm{N}$ and $\mathrm{C}$ isotopes over a very short length scale, observed in some eclogitic and peridotitic diamonds, are still under discussion. Such fluctuations have been mainly detected in the optically inhomogeneous zones consisting of either narrow subzones of $1 \mathrm{aA}$ and $\mathrm{N}$-free (type II) diamond (Bulanova et al., 2002), or in the plastically deformed zones with gigantic platelets. At present it is unclear whether these large and erratic variations in $\mathrm{N}$ - isotope composition in single diamonds result from a change in their growth conditions.

Some of the observed $\mathrm{N}-\delta^{13} \mathrm{C}-\delta^{15} \mathrm{~N}$ co-variations in the core- rim traverses of the diamonds are consistent with thermodynamic models for diamond growth from $\mathrm{C}-\mathrm{N}-\mathrm{H}-\mathrm{O}$ vapour under varying P-T- $\mathrm{fO}_{2}$ conditions (Deines, 1980; Deines et al., 1989). Thus, peridotitic diamonds 3648 and 4160 and eclogitic stone 1153 with core- rim trends evolving to heavier $\mathrm{C}$ and lighter $\mathrm{N}$ isotope compositions (Fig. 1-3) could be interpreted as growing from $\mathrm{CO}_{2}$-rich fluid during fractionation caused by increasing $\mathrm{fO}_{2}$. The other eclogitic diamonds, showing progressive decrease of $\delta^{13} \mathrm{C}$ towards the diamond rims, could represent growth from a $\mathrm{CH}_{4}-$ dominated fluid. However this does not account for the simultaneous decrease of $\mathrm{N}$ content and isotopic compositions. The lack of appropriate thermodynamic models for $\delta^{15} \mathrm{~N}$ behaviour during diamond growth does not currently allow us to evaluate the $\mathrm{N}$ isotopic data in the context of fluid evolution.

\section{REFERENCES}

Bulanova, G.P., 1995. The formation of diamond. J. Geochem. Explor. 53, 1-23.
Bulanova, G.P., Pearson, D.G., Hauri, E.H and Griffin, B.J. 2002. Carbon and nitrogen isotope systematics within a sector-growth diamond from the Mir kimberlite, Yakutia. Chem. Geol. 188, 105-123.

Deines, P., 1980. The carbon isotopic composition of diamonds: relationship to diamond shape, colour, occurrences and vapour composition. Geochim. Cosmochim. Acta. 44, 943-961.

Deines, P., Harris, J.W., Spear, P.M., Gurney, J.J. 1989. Nitrogen and $\delta^{13} \mathrm{C}$ content of Finch and Premier diamonds and their implications. Geochim. Cosmochim. Acta. 53, 1367-1378.

Harte, B., Fitzsimons, C.W., Harris, J.W. and Otter, M.L. 1999. Carbon isotope ratios and nitrogen abundance in relations to cathodoluminescence characteristics for some diamonds from Kaapvaal province, $\mathrm{S}$ Africa. Min. Mag. 63, (6), 829-856.

Hauri, E., Pearson, G., Bulanova, G.P. and Milledge, H.J. 1999. Microscopic variations in $\mathrm{C}$ and $\mathrm{N}$ isotopes within mantle diamonds revealed by SIMS. Proc. $7^{\text {th }}$ IKC, Cape Town, SA, vol. 1, pp. 341-347.

Hauri, E,H., Wang, J., Pearson, D.G. and Bulanova, G.P. 2002. Microanalysis of $\delta^{13} \mathrm{C}, \delta^{15} \mathrm{~N}$ and $\mathrm{N}$ abundances in diamonds by secondary ion mass spectrometry. Chem. Geol., 185, 149-163.

Navon, O. 1999. Diamond formation in the Earth's mantle. Proc. $7^{\text {th }}$ IKC, Cape Town, SA, vol. 2, pp. 584-605.

Pearson, D.G., Shirey, S.B., Bulanova, G.P., Carlson, R.W., Milledge, H.J., 1999. Re-Os isotope measurements of single sulphide inclusions in Siberian diamond and its nitrogen aggregation systematics. Geochim. Cosmochim. Acta. 63, no. 5, 703-711.

Taylor, W.R., Bulanova, G.P., Milledge, H.J. 1995. Quantitative nitrogen aggregation study of some Yakutian diamonds: constraints on the growth, thermal, and deformation history of peridotitic and eclogitic diamonds. Ext. Abstr. $6^{\text {th }}$ Int. Kimb. Conf., Novosibirsk, Russia, pp. 608-610.

Taylor, L.A., Milledge, H.J., Bulanova, G.P., Snyder, G.A. and Keller, R.A. 1998. Metasomatic eclogitic diamond growth: evidence from multiple diamond inclusions. Int. Geol. Rev. 40, no. 8, August, 663676.

Contact: GP Bulanova, 10 Upper Camden Place, Bath BA1

5HX, United Kingdom, E-mail:

galina_bulanova@hotmail.com 